\title{
DIREITO POSITIVO E PLENITUDE DA CONDIÇÃO HUMANA: LEI E OBEDIÊNCIA NO PENSAMENTO DE HANNAH ARENDT
}

João Maurício Adeodato ${ }^{1}$

\section{RESUMO}

A tese aqui defendida é que se pode ler na obra de Hannah Arendt a idéia de que o direito positivo é uma garantia da esfera política e, assim, um elemento importante para o pleno exercício das faculdades humanas. Esse direito não tem um conteúdo ético superior ou definido, mas há limites antropológicos que não deve transgredir. Um desses é o levar em consideração a pessoa do outro, respeitar o próximo.

Palavras-chave: Condição Humana. Direito Positivo. Obediência. Poder.

\section{INTRODUÇÃO: vita activa e modernidade.}

Pretende-se aqui analisar um aspecto de como Hannah Arendt interpreta o desenvolvimento da sociedade ocidental em direção à modernidade, no que concerne à organização do direito como espaço público, a partir de uma ontologia da condição humana, dividida em esferas de atividade construídas sobre uma dicotomia básica entre os espaços público e privado.

Hannah Arendt oferece uma das melhores saídas aos problemas éticos da modernidade, mormente no que diz respeito aos limites que se imporiam a todo poder constituinte, por mais originário que fosse.

Quando se estuda o pensamento de um autor, é óbvio que o objetivo deve ser compreendê-lo o mais fielmente possível e não procurar apontar-lhe eventuais inconsistências, pois é de supor que nelas não estarão as contribuições mais importantes. Caso contrário, não há sentido em tê-lo escolhido como guia para questionar este ou aquele problema, melhor ler outra coisa. Daí que, se algumas contradições forem observadas na obra de Hannah Arendt, isso se deve apenas à 
tentativa de melhor esclarecê-las, mesmo que apenas para alertar quem porventura queira estudar pessoalmente essa obra.

A tese aqui defendida é que se pode ler na obra de Hannah Arendt a idéia de que o direito positivo é uma garantia da esfera política e, assim, um elemento importante para o pleno exercício das faculdades humanas. Esse direito não tem um conteúdo ético definido, mas há limites antropológicos que não deve transgredir. Um desses é o levar em consideração a pessoa do outro, respeitar o próximo.

Essa é a principal questão jusfilosófica: os fundamentos éticos do direito constitucional, eventuais limites prévios aos conteúdos éticos do direito positivo.

Nesse sentido da ontologia da condição humana, é preciso situar a interpretação arendtiana de modernidade, partindo dos conceitos de trabalho (labor), produção de objetos (work) e ação (action), posto que ela associa essas esferas da vita activa à divisão organizacional originária da vida gregária (privada e pública).

Para entender o pensamento de Arendt, os dois principais pressupostos metodológicos aqui adotados são a fenomenologia terminológica ou conceitual, e a dignidade ontognoseológica do mundo das aparências ${ }^{2}$. Além desses pressupostos, as idéias de Arendt mais importantes para esse tema aqui escolhido são a penetração do social na esfera pública, deturpando-a, e o direito moderno como objeto (fruto do work) ou até bem de consumo (fruto do labor), naquilo que considera uma malfadada instrumentalização da política ${ }^{3}$.

Vai-se, portanto, deixar de lado a vita contemplativa, gnoseológica, apesar de sua importância na obra de Arendt, para concentrar o estudo sobre a vita activa da condição humana, a qual pode ser ilustrada pelo esquema seguinte:

\begin{tabular}{|l|l|l|l|}
\hline Labor & Vida & Planeta Terra & Social \\
\hline Atividades & $\begin{array}{l}\text { Condições } \\
\text { Específicas }\end{array}$ & $\begin{array}{l}\text { Condições } \\
\text { Gerais }\end{array}$ & Espaços \\
\hline \hline Work & Mundanidade & Mortalidade & Privado \\
\hline
\end{tabular}




\begin{tabular}{|l|l|l|l|} 
Action & Pluralidade & Natalidade & Público \\
\hline
\end{tabular}

Pois bem. Para Hannah Arendt uma das características da modernidade e uma fonte importante de seus problemas é a confusão entre essas esferas originárias da vita activa.

\section{LEI E DIREITO}

A língua inglesa por vezes designa com o mesmo termo, law, os significados "lei" e "direito", o que sempre dificulta a tradução, principalmente quando o contexto não é claramente exclusivo. Obviamente, há os dois sentidos distintos, a lei, ou norma jurídica legislada, entendida como uma das manifestações do direito. A rigor, é difícil um sinônimo de direito: por exemplo, as decisões dos tribunais são law no sentido mais geral, mas não o são no outro sentido. ${ }^{4} \mathrm{Em}$ alemão, a separação é mais precisa (Recht e Gesetz), como em português, mas os textos de Arendt aqui consultados, originalmente escritos em inglês, contribuem para alguma confusão. Como Arendt não tinha preocupações tão especificamente jurídicas e não se debruçou sobre este problema terminológico, fica difícil dizer, em determinadas ocasiões, quando ela se refere a law em uma ou outra de suas acepções.

Hannah Arendt entende a lei em sua conotação grega clássica, como um objeto, produzido pela atividade do homo faber, que fornece a estrutura material do direito e da política e demarca o espaço público. Tachar Arendt de legalista, contudo, é falso. A lei, como todo objeto, só tem sentido por meio da ação humana, de sua manifestação no mundo das aparências, mediante palavras, atos, fatos do ser humano, enfim. Lembre-se que nem o espaço público é produto automático da simples existência da lei, nem ao espaço político é suficiente a existência do mundo público.

A lei, na Grécia clássica, parece ter sido originalmente identificada com a linha externa, a fronteira que separa os diversos sujeitos em sua esfera privada, ao mesmo tempo delimitando o espaço que é comum a todos: sem a lei não pode haver 
a cidade, a polis, mas apenas um mero conglomerado de casas, de prédios. A lei forma o alicerce das esferas pública e política, embora com elas não se confunda e Ihes seja anterior, tendo um significado espacial em suas origens etimológicas; Arendt chama atenção para a relação entre a lei, o direito, e o muro, a parede, no termo grego nomos. É por isso que o legislador não precisava sequer ser cidadão, podendo mesmo ser um estrangeiro. ${ }^{5}$

Note-se a diferença entre as acepções grega e romana para o termo lei, adverte Arendt. Para os romanos, a lei não é uma atividade pré-política, mas indica, além de manifestação do poder legítimo, a própria constituição do pacto de fundação da cidade, num sentido mais usitado a ouvidos modernos do que ao grego. A lex demarca o pacto político entre os patrícios, descendentes dos invasores provenientes de Tróia, e os plebeus, descendentes dos nativos da península italiana. ${ }^{6}$ Mas nem na Grécia nem em Roma a legitimidade do direito depende de uma instância transcendente, vale dizer, a infra-estrutura da política é mundana, ainda que a equiparação entre legitimidade e efetividade do realismo contemporâneo seja inteiramente estranha ao pensamento clássico. $O$ fato de 0 ato legislativo grego ser considerado pré-político, por seu turno, não indica qualquer transcendência; pelo contrário, enfatiza o caráter artificial, no sentido de feito pelo ser humano, da lei e do direito em geral.

$\mathrm{Na}$ maioria das vezes em que usa o termo law, Hannah Arendt refere-se ao sentido grego, da atividade legislativa como produto do homo faber. Quando quer falar da realidade jurídica em sentido mais amplo, ou "direito", ela menciona a política como o campo no qual se dá a teia das interações humanas: "a idéia de que a atividade política é fundamentalmente o ato de legislar, embora de origem romana, é essencialmente moderna e encontrou sua mais alta expressão na filosofia política de Kant."” Esse é o sentido de "lei" para ela, não de "direito".

A lei constitui a infra-estrutura do político. Justamente porque não pensava e não podia julgar, Eichmann - como todo burocrata - apegava-se a normas, não como orientações, mas como dogmas inquestionáveis de conduta. Quer dizer, o legalismo de Hannah Arendt não se dá nos termos do legalismo da Escola da Exegese francesa: ela vê como necessária a problematização do conteúdo de cada 
caso individual, há oportunidades em que as leis e normas pré-existentes, em geral indispensáveis, não são de qualquer valia e devem ser deixadas de lado. Essa a "capacidade para pensar",

Mesmo que a tradição clássica não justifique apelo a instâncias transcendentes, Arendt afirma que só Montesquieu, dentre os autores prérevolucionários, não introduziu na esfera política um poder absoluto - divino ou despótico - e definiu as leis como rapports, relações. O apelo a instâncias transcendentes, ainda segundo Arendt, é em parte herança do absolutismo, que o jusnaturalismo teológico e a tese do direito divino dos reis, de certa forma, alimentaram. Aí aduz: "Só na medida em que entendemos por lei um comando, ao qual os seres humanos devem obediência independentemente de seu consentimento e acordos mútuos, a lei requer uma fonte de autoridade transcendente para sua validade, isto é, uma origem que deve estar além do poder humano."9

2 GARANTIA DE EXPECTATIVAS: a lei como publicização da capacidade de prometer.

Política e direito, se bem que estreitamente ligados, não se confundem; enquanto a política pretende-se modificadora da realidade, o campo do infinitamente improvável, o direito restringe essas modificações, contrabalançando-as (note-se como Arendt quase sempre pensa em law como lei) : "Os mais importantes dentre os fatores estabilizadores, mais duradouros que costumes, usos sociais a tradições, são os sistemas legais que regulam nossa vida no mundo e nossas relações diárias uns com os outros." $E$ é essa a função da lei e do direito em geral: "As leis positivas, portanto, destinam-se fundamentalmente a funcionar como fatores estabilizadores para os movimentos sempre em mudança dos seres humanos."11

Prometer é a maneira peculiar de ordenar o futuro, de torná-lo confiável na medida do humanamente possível; ordená-lo, mas não constituí-lo, pois a imprevisibilidade do futuro faz com que as promessas jamais sejam absolutas, pois é sempre possível quebrá-las. A promessa permite controlar agora expectativas futuras de comportamento. Por isso mesmo, além da capacidade de fazer 
promessas, os seres humanos são dotados da faculdade de mantê-las e cumpri-las. Mas o poder de prometer de nada adianta com relação ao passado: para conciliarse com esta dimensão temporal o ser humano dispõe do poder de perdoar e do poder de mentir, isto é, descumprir promessas ${ }^{12}$. Essas três faculdades, antropologicamente privadas, já que não se fala ainda de poder em sentido político, não vêm de fora, mas são remédios da própria ação para caracteres essenciais dela mesma: a promessa estabiliza o futuro e remedia a imprevisibilidade da ação; o perdão estabiliza o passado e remedia a irreversibilidade dos atos humanos; e a possibilidade da mentira cria a necessidade da promessa.

Essas capacidades da ação prendem-se à condição desta, a pluralidade, à presença efetiva de outros, já que ninguém pode prometer, perdoar ou mentir a si mesmo. Segundo Arendt, enquanto o perdão se tem mantido, desde que revelado por Jesus de Nazaré, fora do âmbito público, a capacidade de prometer, consubstanciada pelos romanos na máxima pacta sunt servanda, adquiriu relevância pública há tempos imemoriais. Embora todas existam em função da pessoa do outro e impliquem numa ação, só a faculdade de prometer tem tido grande importância na esfera política e no direito.

Enquanto o poder é gerado quando as pessoas se reúnem e agem em conjunto, e o espaço das aparências é a realidade onde se dá esse poder, pois a possibilidade de prometer e cumprir mantém os seres humanos juntos, ainda que fisicamente separados ou inativos diante da mentira.

Já que tanto a lei quanto a promessa são fatores estabilizadores da ação, pode-se aqui ligar o direito à faculdade de prometer; é através do direito que o incessante fluxo de recém-chegados (the newborn) toma pé nas regras do jogo de promessas mútuas que compõem as fronteiras da cadeia de ações e reações humanas. Embora mutável, o direito positivo o é menos do que a ação e o próprio poder precisa dele, na medida em que organiza o espaço político.

Resta a questão de se a legitimidade em Hannah Arendt tem instâncias de referência de conteúdo ético definido, as quais não se podem resumir no mero respeito à legalidade ou ao cumprimento de promessas, nem tampouco podem ser 
medidas por quaisquer relações ou funções que eventualmente desempenhem, haja vista que todos esses são critérios formais e procedimentais.

O poder legítimo não se resume a eles, assevera Arendt, mas, diante do inusitado da ação humana que é seu fundamento, necessita de limites razoavelmente rígidos e facilmente identificáveis, os quais são construídos mediante o direito positivo: uma vez asseguradas as bases que permitam a plenitude da condição humana, segundo essa antropologia otimista, todo ser humano é capaz de juízo político e o consenso de apoio ao poder deixa de ser algo fictício. Aí o problema da relação entre legalidade e legitimidade.

\section{CONSTRUINDO UM DEBATE ENTRE ARENDT E UMA FORMA DE POSITIVISMO}

É certo que Arendt não se insere entre os assim chamados positivistas. Não obstante, ela defende algumas idéias comuns aos autores habitualmente classificados nessa perspectiva, muito embora o tom geral de sua obra e a conotação corrente do termo não permitam exatamente classificá-la como tal. Ela recusa inserir-se na dicotomia entre juspositivismo e jusnaturalismo: "O freqüente dilema - ou a lei é absolutamente válida e daí necessita, para sua legitimidade, de um legislador imortal, divino, ou a lei é simplesmente um comando com nada por trás de si senão o monopólio estatal da violência - é uma ilusão."13

A legitimidade da lei, seu fundamento de validade, vem, entre outros fatores, da velha e mundana máxima romana: pacta sunt servanda. Coerentemente, Arendt já observara antes, a respeito dos regimes totalitários ${ }^{14}$, que a negação da legalidade consiste exatamente em derivar sua legitimidade de uma "legalidade" superior à única legalidade, a positiva. O direito só o é se positivo e acima dele não existe verdade, só o arbítrio. Sabe-se que a idéia central do jusnaturalismo é exatamente derivar sua legitimidade de uma ética superior à positiva ${ }^{15}$.

Em outro ponto Arendt também está de acordo com os positivistas: na expressa separação entre moralidade e legalidade, entre a moral, de um lado, e a política e o direito, de outro. A moral, que se revela na consciência, difere do direito por ser, em 
princípio, apolítica. Interpretando Kant, Arendt diz que mesmo uma "raça de demônios" pode permanecer dentro dos limites razoáveis fixados pelo direito e pela política, isto é, podemos ter maus seres humanos moralmente falando - e ainda assim bons cidadãos. As proposições morais só são evidentes para aqueles que pensam e são capazes de julgar, enquanto o direito precisa ser evidente para todos, tem que aparecer como linha demarcatória que é. ${ }^{16} \mathrm{O}$ único conteúdo moral do consentimento que apóia o poder político-jurídico, como aliás o conteúdo moral de todos os acordos e contratos, é a simples disposição de cumprir promessas, de dar e manter garantias quanto a uma futura conduta. Em outros termos: garantir expectativas.

Ao tentar aqui estabelecer comparações com uma perspectiva positivista, não se quer emprestar a Hannah Arendt parâmetros filosóficos que lhe são estranhos ou exigir-Ihe uma consistência com a qual não achou por bem se preocupar, mas sim mostrar semelhanças. Basicamente não são positivistas a exclusão da força e da violência do conceito de poder, a denúncia contra a manipulação da opinião e a incapacidade para pensar, ameaças permanentes ao ser humano moderno, e a rejeição da burocracia e do sistema de partidos como distorções inadequadas.

O problema é que Arendt sempre se refere ao direito positivo e à lei como se tivessem de fato os caracteres que lhes são atribuídos pela dogmática jurídica e a doutrina oficial, quais sejam, objetividade, imparcialidade, igualdade e neutralidade, dentre outros menos significativos. A história do direito revela que tais atributos são contingentes e que o papel do ordenamento jurídico na política não se dá assim. Muito embora deixe claro que a lei não é suficiente para garantir o poder legítimo, Arendt não considera a hipótese de que essa mesma lei pode prejudicar e até subverter as condições reais da política.

De outro lado, sua insistência sobre as capacidades individuais e o caráter único de cada ser humano, cada ação, cada juízo particular, pode levar a considerações individualistas, incompatíveis com o conceito de poder de Hannah Arendt. Na verdade o individualismo é secundário, na medida em que não importa o quão corretos ou adequados sejam os meus próprios juízo ou ação, sua significação 
política vai depender da persuasão, do exemplo, em suma, do número daqueles que compartilhem de perspectiva semelhante.

Ainda se pode procurar espaço na mesma característica do pensamento de Hannah Arendt para enxergar ali certo elitismo filosófico, ${ }^{17}$ a despeito da defesa que faz da igualdade na esfera política e de afirmar expressamente que a elite política, aqueles que desejam participar, não se confunde com a elite econômica, social, intelectual ou quaisquer outras. A questão não é simples; escaldada pelo sucesso do nazismo, Arendt demonstra claramente seu receio diante da possibilidade de manipulação das maiorias por minorias organizadas, padrões de conduta ou disciplina massificados, propaganda ideológica etc., inclusive em governos que nada têm de totalitários. Se há em sua filosofia uma "aristocracia" latente, é porque Arendt parece realmente acreditar numa espécie de propensão "natural" de alguns para as atividades políticas, embora o critério para a separação seja exclusivamente político e não biológico, econômico, de maioria ou conhecimento técnico. Parece não considerar que essa propensão "natural" nem sempre é encontrada nas pessoas de boa vontade.

Mais ainda, Arendt reconhece que a ação humana caracteriza-se pela processualidade, no sentido de que dá início a uma cadeia de reações que fogem ao controle do primeiro impulso; com acepção um pouco diferente, o conceito de processo é usado para os eventos da natureza, sempre cíclicos, e até para descrever a faculdade de pensar, que só existe enquanto atividade, enquanto se processa.

Margaret Canovan, que arrisca alguns reparos, tem razão quando pergunta por que é tão equivocada a concepção da história como repertório de processos se a história forma-se do registro das ações humanas passadas e se estas são processos. ${ }^{18}$ Mas, como nota essa autora, corretamente, Arendt parece ter em mente conceitos diferentes ao abordar a história dos povos e a processualidade da ação humana isolada; parece claro que uma coisa é entender a ação como processo do seu ponto de partida, do presente se projetando para o futuro; outra é ver a história, o passado, como encadeamento de processos, já que o observador sempre 
está em seu termo final. O erro não jaz propriamente no conceito de processo, mas no tom de inexorabilidade que adquire ao ser aplicado aos fatos históricos.

Por outro lado, a perspectiva que Hannah Arendt tem da esfera política pode parecer utópica olhos contemporâneos. Note-se, não obstante, que ela não pretende exatamente descrever a realidade, mas sim um ideal histórico, determinada concepção do mundo que, não importa se já se tenha realizado, foi percebida e mantida na tradição a despeito da realidade. É difícil acreditar que ela de fato pensava que as elites políticas, no sentido das lideranças a que se refere, tenham alguma vez sido escolhidas pela maior ou menor inclinação de determinados indivíduos à vida pública ou que os inúmeros seres humanos que sempre se preocupam com a prévia liberação das necessidades o fazem por livre escolha ou desprezo pelo espaço político. Mesmo entre aqueles de algum modo remediados, é complicado imaginar uma comunidade na qual a liberdade política de Arendt seja a grande preocupação dos cidadãos. ${ }^{19}$

Não é somente por causa da doutrina liberal que muitos realmente desejam apenas o espaço necessário a sua vida privada e social (os altruístas o desejam a todos) e a política lhes parece um fardo, estando mesmo dispostos a tolerar e sustentar uma burocracia partidária corrupta desde que sejam deixados em paz. Como observa Luhmann, uma preocupação real com a política da parte de um número significativo de cidadãos - quanto ao resultado das eleições, por exemplo acabaria por eliminar as possibilidades de legitimação dos sistemas jurídico-políticos modernos, uma vez que eles funcionam em cima da verificação de que essa preocupação não existe. ${ }^{20}$

É claro que, além da antropologia filosófica, as motivações psicológicas têm um papel fundamental na realidade humana e Arendt não nega isto; o que ela rejeita, e com razão, é que tais motivações tenham qualquer relevância política ou jurídica: quando o direito penal apela às intenções do agente, ou o direito civil resguarda a boa fé, as motivações psicológicas interessam somente e na medida em que se manifestam no mundo das aparências, mediante palavras e atos. A teoria política não parece ter o que fazer com a vontade de poder de Nietzsche, de um lado, nem 
com qualquer sentimento atávico de submissão, servidão voluntária ou necessidade de crer, de outro. ${ }^{21}$

\section{DIREITO E VIOLÊNCIA}

Chega-se aqui a uma das colocações de Arendt que mais frontalmente vai de encontro a um quase consenso entre os cientistas sociais contemporâneos, como ela mesma adverte, e que ajuda a perceber em sua obra um pensamento mais prescritivo do que descritivo: a de que a violência é incompatível com o poder político.

Quer dizer, não apenas a violência, mas a própria coercitividade é afastada da política, a simples possibilidade ou ameaça de violência, a garantia que distingue $o$ direito das demais ordens normativas. $E$ isso apesar de estar plenamente de acordo quanto a outros caracteres tradicionalmente atribuídos à realidade jurídica, como a heteronomia, a alteridade e a exterioridade.

O topos do pacta sunt servanda ocupa a filosofia do direito de longa data e muitas observações já têm sido feitas quanto a seus pressupostos de liberdade e igualdade (que ocorrem na faculdade de prometer em Arendt), nem sempre presentes na realidade jurídica. Acontece que o pacto político pode ser bem leonino, a desigualdade de oportunidades, muito grande e a liberdade de escolha, fictícia. Não é só o fato de nascerem submetidos a pactos políticos que faz os seres humanos aceitarem as regras do jogo. $O$ amor pelas instituições parece visivelmente mais frágil do que a leitura de Hannah Arendt deixa perceber.

Arendt prefere admitir a possibilidade do desaparecimento da liberdade e da ação política da esfera dos assuntos humanos a admitir a violência como componente do universo político. A ameaça de violência pode até ser parte do direito e, mesmo que ele forneça a base da política, cabe a ele e não a ela cuidar da coercitividade; a conduta desviante é um problema jurídico e não político, o máximo que a política pode fazer é questionar a escolha dos parâmetros do ilícito. Mas essa escolha em nada depende da coercitividade, ela é essencialmente livre, a coercitividade vem depois, com o direito positivo. E o preço filosófico a pagar pela 
liberdade e pela exclusão da violência é admitir o ilimitado da natureza humana, o que lhe permite até deturpar-se e acabar com a liberdade.

Daí que a violência, mesmo essencialmente apolítica, pode institucionalizar-se e vai implicar tensão e instabilidade apenas a princípio, na medida em que o ser humano esteja arraigado a uma tradição de liberdade, como na correta tradição ocidental, diz ela, que considera a política como fundação e estabelecimento da liberdade. Argumenta que até o terror, a violência institucionalizada, pode atingir certo grau de estabilidade, como na Alemanha nazista; os espartanos não consideravam violência tomar as crianças sob guarda do Estado ou atirar os recémnascidos inválidos Termópilas abaixo.

A resposta vai estar na tradição, na cultura comum a muitos. Arendt tem consciência de que Aristóteles, Hobbes e ela própria falam de mundos diferentes; a tradição é um guia, um ponto de apoio na aproximação dos objetos, não quer conservar as perspectivas do passado. Pelo contrário, o exame da tradição mostra que ela só permanece em pleno vigor na medida em que cada geração lhe adiciona um novo sentido. Considerar a importância filosófica da tradição não implica conservadorismo. Muito pelo contrário, a tradição só tem sentido com a natalidade e a novidade radical dela decorrente, a imprevisibilidade criativa de cada ser humano.

Mesmo assim, a autora acha possível detectar um ponto de partida e um fio condutor na tradição ocidental, no sentido de constituir a liberdade como universo da legitimidade e o consenso como seu apoio. Embora também haja uma tradição de tirania e de intromissão da violência no mundo das aparências, a tradição da liberdade é preferível pelo simples fato de estar mais de acordo com a condição humana, mormente com a ação que forma a esfera política. Na base está, então, a importância da antropologia e da ontologia da condição humana em Hannah Arendt.

Além da tradição e das garantias ao espaço público político, Arendt parte da convicção de que cada ser humano pode pretender saber o que é melhor para si, desde que assuma responsabilidade por suas palavras e atos. Para isso ele é ontologicamente dotado da faculdade de julgar e formar opiniões pessoais, o que pode gerar o consenso e legitimar o poder; e para estabelecer juízos sobre os fatos 
não é preciso conhecer os escritos dos gregos ou o fio da tradição, basta ter sensibilidade e boa vontade em relação ao mundo exterior.

$\mathrm{Na}$ raiz do conceito de poder em Hannah Arendt, excluída expressamente a violência, está a distinção aristotélica entre techné a praxis, como nota Habermas: ${ }^{22}$ a técnica procura encontrar os melhores meios diante de um fim pré-fixado, a praxis busca os melhores fins. É daí que, do Cristianismo de Paulo de Tarso à moderna teoria geral do direito, vai-se retirar a distinção entre o critério de adequação das regras técnicas e o critério axiológico das normas éticas. Contrariando o modelo teleológico da ação de Max Weber e do positivismo em geral, pelo qual o poder se define segundo o sucesso na indução da conduta do outro, Arendt entende que o consenso propriamente dito não pode ser manipulado ou induzido e que o poder está em função do acordo. Com engodo ou violência, real ou simbólica, não há consenso nem poder, pois a estrutura do poder é comunicacional e dialógica, a da violência é instrumental e monológica. ${ }^{23}$

Parece aqui que as objeções do antigo Habermas à exclusão da violência da política se resumem, em última análise, a uma compreensão diferente sobre os objetivos da teoria política: se se deve pensar o que é e daí abordar a realidade ou se o papel do pensamento é modificar esta realidade, otimizá-la, por assim dizer. Em outras palavras, se o pensamento dessas questões é descritivo, na medida do possível, ou se deve procurar ser prescritivo, primordialmente normativo.

A crítica desse "jovem" Habermas ganha um interesse adicional uma vez que, embora realista no sentido de ampliar a esfera política a ponto de incluir a violência, não identifica de modo algum legitimidade e efetividade. $O$ autor concorda com Arendt, contra Hobbes e Weber, no sentido de que a ação estratégica não é capaz de produzir nem preservar, por si só, o poder (esse tipo de ação é definida como aquela que não se orienta para o entendimento mútuo, mas para o êxito sobre o outro). "Não obstante, não podemos excluir do conceito do político o elemento da ação estratégica. Definiremos a violência exercida por meio da ação estratégica como a capacidade de impedir outros indivíduos ou grupos de defender os seus próprios interesses." ${ }^{24}$ Tal elemento de luta e de competição pelo poder não pode ser afastado da teoria política, afirmava ele. 
Se Hannah Arendt vê no consenso o apoio último das instituições jurídico-políticas, é difícil ao observador moderno concordar quando ela elimina como violência os aspectos estratégicos do poder, tais como as disputas entre as diversas facções ou a coercitividade do direito e das instituições em geral. Sem a relação entre legitimidade e violência estrutural, não é possível entender a exclusão ou neutralização de determinados setores da população da luta pelo poder. Além disso, a rígida separação entre o político e o econômico, conforme apontado, esquece a intermediação do Estado social e administrativo moderno na constituição da esfera pública política: "um Estado, exonerado da elaboração administrativa de matérias sociais; uma política, depurada de questões relativas à política social; uma institucionalização da liberdade pública que independe da organização do bem-estar; um processo radical de formação democrática da vontade, que se abstém em face da repressão social - este não é um caminho viável para nenhuma sociedade moderna."25

O problema era então, para Habermas, como diferenciar quando a inevitável ação estratégica está ou não apoiada em algum consenso. E a desvantagem de Hannah Arendt está em não poder oferecer um critério mais palpável, por não aceitar a possibilidade da verdade na política e tampouco admitir a violência.

Parece que os reparos do jovem Habermas partem de pressupostos incompatíveis com os do pensamento de Hannah Arendt: em primeiro lugar, para ele o objeto de reflexão parecia ser o efetivo, a descrição da realidade contemporânea tal como ela é; depois, a convicção de que a filosofia clássica, em lugar de servir de guia, é inadequada à realidade contemporânea e ao desenvolvimento do espaço público; finalmente a afirmação de Habermas de que o efetivo não é hoje o discurso dialógico, mas sim um contexto comunicacional no qual a ação estratégica e a violência estrutural têm papéis preponderantes, se não na gestação, pelo menos na aquisição e no exercício do poder político. Esses pontos opõem uma concepção descritiva a uma prescritiva, mas não perspectivas epistemológicas, de um lado, a politico-éticas, de outro. ${ }^{26}$ 
A solução de Habermas, como ele mesmo se apercebe, não satisfaria Hannah Arendt: "A partir desta reflexão, segue-se que não podemos explicar a pretensão de validade das normas sem recorrer ao acordo motivado racionalmente ou, no mínimo, à convicção de que o consenso sobre uma determinada norma possa efetuar-se através de razões." ${ }^{27}$

Mas se a crítica de Habermas falha pelos pressupostos, ele certamente tem razão quanto à possibilidade de uma perspectiva das ciências humanas mais direta e menos participativa, tal como era a sua própria. Claro que todo pensar é, em certa medida, apaixonado, é ao menos intencional, no sentido da consciência do problema, de Nicolai Hartmann, ou da pré-compreensão, de Heidegger, Gadamer e Hannah Arendt. Só que daí a opor pensamento personalizado a uma objetividade puramente lógica vai uma grande distância. Uma abordagem prescritiva é tão válida quanto uma descritiva, desde que o leitor isento e atento separe os fatos da advocacia do autor que lê. Arendt não ilude ninguém sobre a situação do ser humano moderno, mas quer mais do que descrevê-la, quer otimizá-la. Quando Kelsen diz que o regime nazista seria um sistema jurídico, a perspectiva filosófica é inteiramente diferente.

Sabe-se que autores diversos como Max Weber, Karl Deutsch e até Hermann Heller $^{28}$ argumentam que a obediência pode ser obtida "por apatia, terror ou interesse". Hannah Arendt não nega este fato, mas procura atacar o argumento na raiz conceitual: o poder não se mede pela relação comando/obediência, justamente porque a obediência pode ser obtida por esses outros meios mencionados. Quanto à realidade do poder hoje, diria ela, estão todos de acordo. Arendt se insere contra a posição dominante quando se pergunta o que fazer após a verificação da realidade, em termos de uma filosofia política.

Nada obstante, aqui não se vai descartar a exigência de rendição à realidade que prega o positivismo realista contemporâneo. É um fato, argumentado alhures ${ }^{29}$, que, com o monopólio estatal da produção de normas jurídicas, a supremacia da lei e a positivação do direito, a realidade jurídico-política esvaziou-se de conteúdo e deixou-se penetrar pela ascensão do Estado social e administrativo moderno. Mas esse não é um fato a ser deplorado. Adotar uma visão realista do direito e da política 
não significa pregar o conformismo ou cooperar intelectualmente com a opressão; significa apenas reconhecer que a coercitividade (do lado do direito) ou a possibilidade de ação estratégica (do lado da política) não podem mais ser excluídas das considerações teórico-científicas, pelo menos depois de Maquiavel e Hobbes. Mesmo que seja para combatê-las. Não adianta aludir a instâncias superiores quando estas não são suficientes para frear os impulsos humanos, os limites da força têm que se respaldar em uma força contrária. O âmbito consensual ou "racional" não parece esgotar todas as perspectivas que se possa ter da política.

\section{CONCLUSÃO: poder e obtenção de obediência.}

Conclui-se que a expressão "poder" é empregada diante de quatro experiências concretas, as quais parecem fornecer meios de induzir outros sujeitos a determinada conduta: a persuasão, a autoridade, o engodo e a força. Essas quatro formas não são mutuamente excludentes na realidade, podendo aparecer combinadas; ao mesmo tempo, elas não implicam sempre aceitação ou rejeição absolutas da mensagem tal como é transmitida, ou seja, alguém pode se deixar persuadir por uma parte do discurso e recusar o restante, por exemplo. Pode-se ser enganado quanto a uma parte do discurso e forçado a aceitar outras... E assim por diante.

A persuasão, segundo a lição de Hannah Arendt, a atividade política por excelência na Grécia clássica, é a única dessas experiência humanas que pressupõe a igualdade de condições entre as partes, dizendo respeito predominantemente ao conteúdo da mensagem que é comunicada, como quando se escreve aqui sobre filosofia do direito para persuadir o leitor de uma opinião. Outra maneira de provocar adesão a certo parâmetro de conduta é a autoridade, segundo Arendt trazida ao mundo político pelos romanos, a qual pressupõe uma desigualdade entre as partes, não em função do conteúdo da mensagem, mas sim da própria situação do emissor, mutuamente reconhecido competente para exigir aquela conduta, como no caso de se aceitarem as determinações estilísticas do professor de violão, por exemplo. Arendt afirma que a autoridade praticamente desapareceu do horizonte político contemporâneo. 
Em terceiro lugar, uma espécie pelo menos aparente de consenso pode ser obtida através do engodo. Aí situações fáticas são omitidas, encobertas e mesmo deturpadas, e o receptor não consegue sequer compreender o sentido real da mensagem ou prever-lhe, na medida do possível, as conseqüências; incluem-se aqui a exclusão do sistema educacional, a propaganda massificadora, a neutralização das preferências individuais, a oposição de dificuldades à participação e à discussão das decisões a serem tomadas, o controle e seleção de informações etc.

Finalmente, o poder também se pode respaldar na força, no presente contexto entendida como a possibilidade de aplicação (coercitividade) ou o próprio uso da violência (coação). Claro que esses conceitos têm diversos sentidos nos diferentes autores; fala-se de violência agora, contudo, como o ato da força, não apenas a compulsão física que obtém obediência imediata, mas também a fome, o controle da desigualdade de oportunidades, a instabilidade no emprego, a pessoa amada que ameaça abandonar o parceiro e assim por diante. Todos estes são atos de força, a virtualidade de realização de qualquer tipo de violência.

Deve-se ter presente que essa visão do problema contraria Hannah Arendt desde os pressupostos, ela diria que aqui se aplicam indistintamente ao poder critérios de bases consensuais (a persuasão e a autoridade) e critérios apoiados na categoria de meios e fins, inadequada.

Analisar quais dentre essas - e as demais - formas de indução do comportamento jurídico-politico é legítima ou ilegítima, pior ou melhor, constitui outro problema, bem menos evidente. Em termos descritivos, parece que a realidade jurídico-política não se resume, infelizmente, à persuasão e autoridade. Nem sequer pode-se observar uma estabilidade maior para regimes políticos que eventualmente teriam por base as duas formas que Arendt considera legítimas.

O leitor que espera uma resposta conclusiva ao problema da legitimidade para se situar diante das questões cruciais da modernidade, contudo, não se deve decepcionar, pois pode absorver a lição principal que Hannah Arendt transmite, para 
além de sua própria teoria política: pensar e julgar por si mesmo para formar sua opinião.

A inclusão da pura violência, a equiparação da legitimidade à efetiva obtenção da obediência, portanto, afastaria por completo qualquer possibilidade de tratamento do problema da legitimidade. Unir a legitimidade à violência significaria reduzi-la a uma palavra oca, no sentido de Ross ${ }^{30}$. Mas a ameaça ou mera possibilidade de dano futuro, que não se confunde com a violência atual, parece ser importante na legitimação das expectativas do presente, contrariando a perspectiva de Hannah Arendt.

Deve-se ressaltar que muitos defensores do legalismo exegético, sem propriamente pensar no conteúdo filosófico, querem defender algum tipo de conteudismo tradicional; partem, corretamente, do princípio de que, uma vez determinado o conteúdo das normas superiores, o conteúdo das inferiores, e daí o próprio direito efetivo, estarão, de alguma maneira, eticamente delimitados. Por isso a preocupação constitucional, procurar fazer com que a norma superior tenha o conteúdo que se deseja ver observado na realidade. O problema dos primeiros conteúdos éticos, porém, não é resolvido pelo pragmatismo inerente ao principio da legalidade. problema da legitimidade é pré-constitucional.

A solução legalista, pelo menos em sua versão democrática, baseia-se no princípio da maioria. Esse princípio formal é circunstancial e pode ser perfeitamente dispensado pelos regimes não-democráticos, nos quais a legitimação é conseguida por outras vias, apartadas do processo legislativo e eleitoral. ${ }^{31}$ Mesmo nas democracias modernas, contudo, o princípio da maioria não parece suficiente.

Com efeito, nas atuais condições do direito positivado não há lugar para a antiga distinção entre o tyrannus ab exercitio e o tyrannus absque titulo: se o único limite é a legalidade, e o princípio da legitimidade plebiscitária que a ela subjaz nas democracias, só existe tirania quanto à forma de aquisição do poder, jamais quanto ao seu exercício, como o conceito normativista de revolução se vê obrigado a reconhecer. $^{32}$ 
A maioria sempre poderá ilegalizar as minorias; nenhuma "ficção normativista de unidade" impedirá que as facções em disputa se apoderem daquele fragmento do texto constitucional que Ihes pareça apropriado a obter vantagens, tudo em nome da constituição. Nenhum princípio de legitimidade pode "sobreviver a semelhante degradação em ferramenta técnico-funcionalista." ${ }^{\text {"33 }}$ Ainda que não considere as inúmeras vantagens da legalidade democrática, a crítica de Schmitt à democracia é procedente nesse aspecto.

O problema central, segundo a tese aqui defendida, é que, embora o grosso das doutrinas contemporâneas que se concentram sobre a legitimidade tenham há muito enterrado os jusnaturalismos, elas ainda se debatem com alguns de seus legados (mesmo que sejam herança do absolutismo, como quer Arendt). $\mathrm{O}$ mais importante deles, para a temática abordada, parece ser a procura de um conteúdo universal único como instância de referência para o poder jurídico-politico.

Note-se que Hannah Arendt aceita que o poder não se legitima a partir de fatores externos, os critérios precisam ser imanentes, estão na própria estrutura da ação e demais faculdades humanas. Tampouco quer dizer que o fundamento de legitimidade seja único, absoluto e muito menos infenso a variações no tempo e no espaço: "[...] se nosso futuro dependesse... de uma instância última que, de cima, decidisse por nós (e aí a questão é, naturalmente, quem vai reconhecer essa instância última e quais serão as regras para reconhecê-la - aqui você de fato tem um regresso infinito [...]) eu seria totalmente pessimista. Se este é o caso, então estamos perdidos. Porque isso realmente exige que um novo deus apareça [...] $]^{34}$ Ela adota uma atitude cética quanto a um referencial último e aí assemelha-se ao positivismo contemporâneo.

A solução no outro extremo, a identificação entre legitimidade e efetividade da obediência, essa Hannah Arendt recusa expressamente. Uma perspectiva assim, com toda sua oposição ao jusnaturalismo, parte de premissa semelhante por resultar da decepção em não encontrar um parâmetro definitivo. Como isso não existe muito embora ela acredite que haja instâncias -, corre-se o risco de cair em um ceticismo que tira todo sentido não só à questão da legitimidade mas também, se levado às últimas conseqüências, à própria vida humana. Além de não universal, a 
instância de referência da legitimidade não é sequer única: são critérios frágeis, pouco precisos, variáveis. Sem que seja necessário "saltar sobre nossas próprias sombras", é no mundo humano das aparências que as soluções devem ser procuradas.

Ao leitor desapontado com a falta de uma posição definida e definitiva sobre o conteúdo da legitimidade e sobre outras questões correlatas, lembre-se de que há uma diferença básica entre o que Karl Manheim denomina relacionismo e um completo relativismo cético. ${ }^{35}$ Claro que o conhecimento é condicionado pelas condições da época e do meio que o produzem; as divergências entre os conceitos de legitimidade oferecidos por Tomás de Aquino, Maquiavel ou Locke não se devem apenas a sua originalidade ou a diferenças de perspectivas, mas também ao fato de esses autores terem vivido e pensado em ambientes completamente distintos: "Conhece-se o mundo através de muitas orientações diferentes, porque existem muitas tendências de pensamento simultânea e mutuamente contraditórias (de modo algum de valor igual), lutando entre si, com suas diferentes interpretações da experiência 'comum'. Não há de se encontrar, portanto, a chave deste conflito no 'objeto em si mesmo'."36

Pode-se mais uma vez dizer, com Manheim, que a ausência de uma posição definitiva a respeito do problema da legitimidade "[...] não significa que não haja critérios de verdade e erro em uma discussão [...] mas é da natureza de certas afirmativas a impossibilidade de se as enunciar de modo absoluto, mas apenas em termos da perspectiva de uma dada situação." ${ }^{37}$

Hannah Arendt já foi tachada de saudosista, acusada de guardar uma "nostalgia helênica", pregando romanticamente uma idade de ouro política na Antigüidade grega clássica, a qual absolutamente não teria existido ${ }^{38}$.

Esse "desaparecimento da esfera pública" e essa "ascensão do social", que Hannah Arendt deplora, parecem ser reflexos de uma complexidade social cada vez maior no mundo contemporâneo. O preço que o direito moderno paga é sua "instrumentalização", o que, no jargão da autora, insere-o na esfera da produção de objetos - work - e transforma-o até em bem de consumo - esfera do labor. A 
formalização, a procedimentalização e o abandono do conteúdo ético da justiça são estratégias bem sucedidas nesse processo de auto-referência do direito.

Isso porque, na modernidade, desaparecem as bases axiológicas comuns, daí o problema da legitimidade ter se tornado crucial. É isso que incomoda Hannah Arendt e lhe dá o tom nostálgico. A dogmatização do direito na modernidade emancipou-o de conteúdos axiológicos prévios, negou a norma válida em si mesma, interpretando assim a intransponibilidade entre ser e dever ser de Kant. Mas paga o preço da carência de legitimação.

O positivismo escamoteia o problema da legitimidade ao declará-lo fora do sistema jurídico ou ao equipará-lo instrumentalmente à legalidade e também é assim que a praxis dogmática do direito "resolve" a questão. Não é função do jurista discutir os conteúdos axiológicos, afirma o positivista, tarefa da qual se desincumbiria o sistema político, autopoieticamente organizado. Ocorre que, com a complexidade sempre crescente, essa "solução" moderna não mais satisfaz e esse um dos desafios da pós-modernidade.

A lição de Hannah Arendt vai no sentido de que o poder legítimo, se não apela a instâncias transcendentes nem tem conteúdo universal estabelecido, define-se por levar em consideração a pessoa do outro, uma vez que a ação, o direito, a política constituem-se na intersubjetividade. Pode-se reconhecer que discurso racional e verdade não são sinônimos e que os critérios de referência indispensáveis ao tratamento do problema da legitimidade serão fixados a cada tempo e lugar estarão no agir conjunto do próprio ser humano. Talvez não seja uma resposta satisfatória, mas parece ser a única possível. Aí resumem-se os prós e os riscos da auto-referência, de um ceticismo pirrônico e de um pensamento tópico ${ }^{39}$.

\section{POSITIVE RIGHT AND HEIGHT OF HUMAN CONDITION: LAW AND OBEDIENCE THE THOUGHT OF HANNAH ARENDT}

\section{ABSTRACT}


This paper argues that the work of Hannah Arendt may be taken as a support to defend the thesis that positive law guarantees the political realm and constitutes an important element to a complete development of human faculties. This law has no superior or definite ethical content, but there are anthropological limits which it should not surpass. One of these is to take each human being in respect and consideration.

Keywords: Human Condition. Obedience. Power. Positive law.

\section{NOTAS}

1 Professor Titular da Faculdade de Direito do Recife (UFPE). Pesquisador $1 \mathrm{~A}$ do CNPq. Mestre e Doutor pela Faculdade de Direito da USP. Professor Convidado e Pós-Doutorado pela Fundação Alexander von Humboldt.

2 Para o conceito de ontognoseologia, REALE, Miguel. Filosofia do direito. São Paulo: Saraiva, 1998, p. 125.

3 ARENDT, Hannah. The human condition. Chicago-London: The University of Chicago Press, 1958. As traduções dos originais são responsabilidade do autor. V. ADEODATO, João Maurício. $O$ problema da legitimidade - no rastro do pensamento de Hannah Arendt. Rio de Janeiro: ForenseUniversitária, 1989, passim.

4 Já no primeiro dos verbetes referentes a law, no Webster's Dictionary, encontram-se os dois sentidos: "a rule of conduct or action established by custom or laid down and enforced by a governing authority; also: the whole body of such rules."

5 ARENDT, Hannah. The human condition. Chicago-London: The University of Chicago Press, s/d, p. 63-64.

6 LAFER, Celso. Hannah Arendt - Pensamento, persuasão e poder. Rio de Janeiro: Paz e Terra, 1979, p. 33-34. Hannah Arendt toma por base a Eneida de Virgílio, como se pode conferir em On revolution. New York: The Viking Press, 1981, p. 186-198 ou no último capítulo de The life of the mind (Willing). New York-London: Harvest-HJB, 1978.

7 ARENDT, Hannah. The human condition. Chicago-London: The University of Chicago Press, s/d, p. 1958, p.. 63.

8 LAFER, Celso. Hannah Arendt - Pensamento, persuasão e poder. Rio de Janeiro: Paz e Terra, 1979, p. 93-94; para uma interessante distinção entre direito constitucional e direito "positivo": PAREKH, Bhikhu. Hannah Arendt and the search for a new political philosophy. Hong Kong: Humanities Press, p. $156 \mathrm{~s}$.

9 ARENDT, Hannah. On revolution. New York: The Viking Press, 1981, p. 189.

10 ARENDT, Hannah. Civil Disobedience, in Crises of the Republic. New York-London: Harvest-HJB, 1972, p. 79.

11 ARENDT, Hannah. The origins of totalitarianism (anti-semitism, imperialism, totalitarianism). New York-London: Harvest-HJB, 1973, p. 463.

12 ARENDT, Hannah. The human condition. Chicago-London: The University of Chicago Press, s/d., p. 236 s. e 247 s.; ARENDT, Hannah. On violence, in Crises of the Republic. New York-London: Harvest-HJB, 1972, p. 92-93.

13 ARENDT, Hannah. On violence, in Crises of the Republic. New York-London: Harvest-HJB, 1972, p. 193.

14 ARENDT, Hannah. The origins of totalitarianism (anti-semitism, imperialism, totalitarianism). New York-London: Harvest-HJB, 1973, p. 460 s.

15 ADEODATO, João Maurício. Ética e retórica - para uma teoria da dogmática jurídica. São Paulo: Saraiva, 2006, p. $121 \mathrm{~s}$.

16 ARENDT, Hannah. Civil Disobedience, in Crises of the Republic. New York-London: Harvest-HJB, 1972, p. 52; para a inadequação dos imperativos morais que apelam a uma "lei superior", v. p. 56. Sobre a evidência das proposições de moral, cf. p. 60-63; também ARENDT, Hannah. Lectures on Kant's Political Philosophy. Chicago-London: University of Chicago Press, 1982, p. 17-18. 
17 CAROUX, Jacques. Quel monde pour 1'homme de masse? Esprit (42). Paris, juin 1980, p. 87; ou PAREKH, Bhikhu. Hannah Arendt and the search for a new political philosophy. Hong Kong: Humanities Press, p. 180.

18 CANOVAN, Margaret. The political thought of Hannah Arendt. New York-London: Harvest-HJB, 1974, p. 108-109.

19 LEBRUN, Gérard. A liberdade segundo Hannah Arendt, in Passeios ao Léu. São Paulo: Brasiliense, p. 58-59.

20 Seria o "alto limiar de indiferença" de LUHMANN, Niklas. Legitimation durch Verfahren. Frankfurt a.M.: Suhrkamp, 1983, p. 185-186.

21 Sobre a vontade de se submeter cf. ARENDT, Hannah. On violence, in Crises of the Republic. New York-London: Harvest-HJB, 1972, p. 138; BIRNBAUM, Pierre. Sur les origines de la domination politique. Revue Française de Science Politique 27 (1). Paris, février 1977, p. 115 s., analisando o Discours de la servitude volontaire de Etienne de la Boétie; e EASTON, David. A crença na legitimidade. Curso de Introdução à Ciência Política, Unidade IV. Brasília: Universidade de Brasília, 1982, p. 105, sobre a necessidade de crer.

22 HABERMAS, Jürgen. O conceito de poder em Hannah Arendt, in FREITAG, Barbara e ROUANET, Sérgio (orgs.). Sociologia. São Paulo: Ática, 1980, p. 100-118. ARISTÓTELES. Tópicos, 6 (145) a 15.

23 Para uma diferença entre o discurso comunicacional, dialógico, e o discurso monológico, cf. FERRAZ Junior, Tercio. Teoria da norma jurídica - Ensaio de pragmática da comunicação normativa. Rio de Janeiro: Forense, p. 20-33 e passim.

24 HABERMAS, Jürgen. O conceito de poder em Hannah Arendt, in FREITAG, Barbara e ROUANET, Sérgio (orgs.). Sociologia. São Paulo: Ática, 1980, p. 112.

25 Idem, p. 110.

26 FERRY, Jean Marc. Habermas critique de Hannah Arendt, Esprit (42). Paris, juin 1980, p. 109-124, simplifica a questão nesse ponto; como diria Arendt, ele também paga o preço das ciências sociais modernas.

27 HABERMAS, Jürgen. Legitimation crisis in late capitalism. Boston: Beacon, 1975, part. III, cap. 2, p. 105; para os problemas que enfrentam os diversos tipos de racionalismo, como o próprio autor mostra, cf. HABERMAS, Jürgen. On theory and practice in our scientific civilization. Theory and practice. Boston: Beacon, 1973, p. 253-282.

28 HELLER, Hermann. Teoria do Estado. São Paulo: Mestre Jou, s/d., p. 237.

29 ADEODATO, João Maurício. Ética e retórica - para uma teoria da dogmática jurídica. São Paulo: Saraiva, 2006, p. 181.

30 ROSS, Alf. Tu-Tu. Trad.: Genaro Carriõ. Buenos Aires: Abeledo Perrot, 1976, p. 32 s.

31 LUHMANN, Niklas. Legitimation durch Verfahren. Frankfurt a.M.: Suhrkamp, 1983, p. nota no 11, p. 160: falando expressamente da "América do Sul do século XX", afirma que as disfunções dos procedimentos legislativo e eleitoral precisam ser supridas por outros caminhos. Para o caso brasileiro, cf. LAFER, Celso. O sistema político brasileiro - Estrutura e processo. São Paulo: Perspectiva, 1975, p. 74, que mostra como um governo com preocupações legalistas, como todo governo moderno, pode pretender se legitimar pela eficiência e pelo exercício efetivo do poder, mesmo sem consideração pelo princípio da maioria. Mas aí já se está fora da legalidade democrática.

32 A expressão "legitimidade plebiscitária" é de SCHMITT, Carl. Legalidad y Legitimidad. Madrid: Aguillar, 1968, p. 44 s.

33 Idem, p. 152. Já depois da segunda guerra e de ter sido acusado de servir de esteio teórico ao nazismo com suas criticas à democracia de Weimar, Schmitt tenta mostrar como a legitimidade plebiscitária viabilizou a ascensão de Hitler. Certamente o princípio é insuficiente para delimitar o direito à resistência.

34 Trata-se de debate entre Hannah Arendt a Hans Jonas, publicado em um volume editado por Melvyn Hill, Hannah Arendt - The recovery of the public world, p. 311-315, apud BEINER, Ronald. Hannah Arendt on judging - Interpretive essay on Hannah Arendt's Lectures on Kant's politicall philosophy. Chicago: University of Chicago Press, 1982, 115. Sobre critérios imanentes para a política: ARENDT, Hannah. Truth and Politics, in Crises of the Republic. New York-London: Harvest-HJB, 1972, p. 240 e 246-247.

35 MANHEIM, Karl. Ideologia e Utopia. Rio de Janeiro: Zahar, 1976, p. 286-330.

36 Idem, p. 291.

37 Idem. p. 304

38 O'SULLIVAN, Noel. Hannah Arendt - A nostalgia helênica e a sociedade industrial. Documentação e atualidade política n ${ }^{\circ}$. Brasília: out./dez. 1977, p. 15-25; e HOBSBAWN, Eric J. 
Hannah Arendt e a revolução, in Revolucionários - Ensaios contemporâneos. Rio de Janeiro: Paz e Terra, 1982, p. 201-208.

39 ADEODATO, João Maurício. Ética e retórica - para uma teoria da dogmática jurídica. São Paulo: Saraiva, 2006, p. 345.

\section{REFERÊNCIAS}

ADEODATO, João Maurício. Ética e retórica - para uma teoria da dogmática jurídica. São Paulo: Saraiva, 2006.

ARENDT, Hannah. Civil Disobedience, in Crises of the Republic. New York-London: Harvest-HJB, 1972.

. Lectures on Kant's Political Philosophy. Chicago-London: University of Chicago Press, 1982.

. On revolution. New York: The Viking Press, 1981.

. On violence, in Crises of the Republic. New York-London: Harvest-HJB, 1972.

. The human condition. Chicago-London: The University of Chicago Press, 1958.

. The origins of totalitarianism (anti-semitism, imperialism, totalitarianism). New

York-London: Harvest-HJB, 1973.

. Truth and Politics, in Crises of the Republic. New York-London: Harvest-HJB, 1972.

BEINER, Ronald. Hannah Arendt on judging - Interpretive essay on Hannah Arendt's Lectures on Kant's politicall philosophy. Chicago: University of Chicago Press.

BIRNBAUM, Pierre. Sur les origines de la domination politique. Revue Française de Science Politique 27 (1). Paris, février 1977.

CANOVAN, Margaret. The political thought of Hannah Arendt. New York-London: Harvest-HJB, 1974.

CAROUX, Jacques. Quel monde pour 1'homme de masse? Esprit (42). Paris, juin 1980 , p. 87.

EASTON, David. A crença na legitimidade. Curso de Introdução à Ciência Política, Unidade IV. Brasília: Universidade de Brasília, 1982. 
FERRAZ Junior, Tercio. Teoria da norma jurídica - Ensaio de pragmática da comunicação normativa. Rio de Janeiro: Forense.

FERRY, Jean Marc. Habermas critique de Hannah Arendt. Esprit (42). Paris, juin 1980, p. 109-124.

HABERMAS, Jürgen. Legitimation crisis in late capitalism. Boston: Beacon, 1975.

. O conceito de poder em Hannah Arendt. In.: FREITAG, Barbara; ROUANET, Sérgio (orgs.). Sociologia. São Paulo: Ática, 1980, p. 100-118.

. On theory and practice in our scientific civilization. Theory and practice. Boston: Beacon, 1973.

HELLER, Hermann. Teoria do Estado. São Paulo: Mestre Jou, s/d.

HOBSBAWN, Eric J. Hannah Arendt e a revolução. In.: Revolucionários - Ensaios contemporâneos. Rio de Janeiro: Paz e Terra, 1982.

LAFER, Celso. Hannah Arendt - Pensamento, persuasão e poder. Rio de Janeiro: Paz e Terra, 1979.

. O sistema político brasileiro - Estrutura e processo. São Paulo: Perspectiva, 1975.

LEBRUN, Gérard. A liberdade segundo Hannah Arendt. In.: Passeios ao Léu. São Paulo: Brasiliense.

LUHMANN, Niklas. Legitimation durch Verfahren. Frankfurt a.M.: Suhrkamp, 1983. MANHEIM, Karl. Ideologia e Utopia. Rio de Janeiro: Zahar, 1976.

O'SULLIVAN, Noel. Hannah Arendt - A nostalgia helênica e a sociedade industrial. Documentação e atualidade política n ${ }^{\circ}$. Brasília: out./dez. 1977, p. 15-25.

PAREKH, Bhikhu. Hannah Arendt and the search for a new political philosophy. Hong Kong: Humanities Press.

REALE, Miguel. Filosofia do direito. São Paulo: Saraiva, 1998.

ROSS, Alf. Tu- Tu. Trad.: Genaro Carriõ. Buenos Aires: Abeledo Perrot, 1976.

SCHMITT, Carl. Legalidad y Legitimidad. Madrid: Aguillar, 1968. 
Aceito para publicação 10/12/2007 